https://doi.org/10.46344/JBINO.2020.v09i5b.07

\title{
A REVIEW ON ROLE OF AYURVEDA FOR IMMUNITY BOOSTERS AGAINST COVID 19
}

Dr. Bhairav B. Tawshikar Kulkarni \& Dr. Shrikant G. Deshmukh

Associate Professor Kayachikitsa Deptt, Ashvin Rural Ayurved College, Manchihill

Professor \& HOD , Kayachikitsa Deptt., CSMSS Ayurved College, Aurangabad

\begin{abstract}
Ayurveda too has its own and the science needs to grow within these limitations and collaborate with other healthcare systems to provide an integrated approach to health and wellbeing the man kind. In present situation COVID 19 pandemic has affected drastically all human beings of all ages. In present manuscript we are discussing regarding the role of Ayurveda to increase immunity of individuals, so that we can effectively fight present pandemic situation.
\end{abstract}

Keywords: Covid 19, Ayurveda, Immunity boosters 


\section{INTRODUCTION}

Coronaviruses are a large family of viruses which may cause disease in animals or humans. Seven coronaviruses can produce infection in people around the world but commonly people get infected with these four human coronaviruses: 229E, NL63, OC43, and HKU1. They usually cause a respiratory infection ranging from the common cold to more severe diseases such as Middle East Respiratory Syndrome (MERS) and Severe Acute Respiratory Syndrome (SARS) and the most recently discovered coronavirus (COVID-19) cause's infectious disease. The virus is typically rapidly spread from one person to another via respiratory droplets produced during coughing and sneezing. It is considered most contagious when people are symptomatic, although transmission may be possible before symptoms show in patients. Time from exposure and symptom onset is generally between two and 14 days, with an average of five days. Common symptoms include fever, cough, sneezing and shortness of breath. Complications may include pneumonia, throat pain and acute respiratory distress syndrome. Currently, there is no specific antiviral treatment or vaccine; efforts consist of symptom abolition supportive therapy. Recommended preventive measures include washing your hands with soap, covering the mouth when coughing, maintaining 1-meter distance from other people and monitoring and self-isolation for fourteen days for people who suspect they are infected. The standard tool of diagnosis is by reverse transcription polymerase chain reaction (rRT-PCR) from a throat swab or nasopharyngeal swab. The infection can also be diagnosed from a combination of symptoms, risk factors and a chest CT scan showing features of pneumonia.

\section{Origin \& Transmission}

Origin and Transmission of COVID-19 The first cases of coronaviruses in human found in 1965 by Tyrrell and Bynoe. They observed that they could passage a virus named B814. It was observed in human embryonic tracheal organ cultures obtained from the respiratory tract of an adult with a common cold symptom. The first cases were seen in Wuhan City of Hubei Province China in December 2019, and have been linked to the Huanan Seafood Market (South China) and the infection has spread to several countries around the world. The novel coronavirus originated from the Hunan seafood market at Wuhan, South China where raccoon dogs, bats, snakes, palm civets, and other animals are sold, and rapidly spread up to 109 countries. The zoonotic source of SARSCOV-2 is not confirmed, however, the sequence-based analysis suggested bats as the main reservoir. The recombination of DNA was found to be involved at spike glycoprotein which assorted SARS-CoV (CoVZXC21 or CoVZC45) with the RBD of another Beta CoV, thus could be the reason for crossspecies transmission and rapid infection. The virus that causes coronavirus disease 19 (COVID-19) is a highly transmittable and pathogenic viral infection and mainly transmitted through contact with respiratory droplets rather than through the air. Primarily people can catch coronavirus 
disease 19 (COVID-19) from others who are infected. A single cough can circulate up to 3.000 droplets. These droplets can land on other people, and covering surfaces around them, however, several smaller particles will stay within the air. the virus is also shed for extended in fecal matter, thus anyone who not washing their hands thoroughly after visiting the toilet, bathroom could contaminate anything they touch like many respiratory viruses, including flu, Covid-19 can be spread by close contact with small droplets released from infected individuals' upper respiratory tract secretions, e.g. sneezing, common cold or coughing from the nose and mouth. That is why to stay more than 1 meter ( 3 feet) away from a person who is sick. The virus can also be transmitted through surface contamination when these droplets land on objects and surfaces around the person and other individual touches these objects or surfaces and further touching their eyes, nose or mouth then these people catch COVID-19.

\section{AYURVEDA AS IMMUNE BOOSTERS to fight against the pandemic:}

Ayurvedic medicine ("Ayurveda" for short) is one of the world's oldest holistic ("wholebody") healing systems. It was developed more than 3,000 years ago in India.

It's based on the belief that health and wellness depend on a delicate balance between the mind, body, and spirit. Its main goal is to promote good health, not fight disease. But treatments may be geared toward specific health problems.

Any time is a good time to think about strengthening your immunity. Cold weather doesn't have to bring on the cold and flu.
The key is to start now with immunityenhancing meals.

What are immunity-enhancing foods? Any food that transforms quickly into ojas is good for immunity. If food creates ama, it's bad for immunity.

Ojas is the end product of complete digestion that creates radiant good health, stable emotions, and immunity. Ama, the digestive impurities caused by eating hardto-digest foods or by unhealthy eating habits, creates the opposite effect - it compromises immunity and health.

Maharishi Ayurveda uses the seed-land theory to explain how immunity works. In this analogy, the human body is like the land, and infection is the seed. Ama and other impurities make the body fertile for infection. If you want to keep the seeds of infection from sprouting, you must take care to create ojas in your body, not ama.

Cook your food in a way that doesn't disturb the food's natural intelligence. For instance, if you add mild spices to cooked vegetables, grains and legumes, the food will convert more quickly to ojas. Spices add good flavor and have a yogavahi property, which means that they support digestion and make the nutrients easily available to the body.

Different spices also have specific immuneboosting properties. Turmeric has an immune-modulating effect, because it is detoxifying and enhances the intelligence of the immune cells. Cumin burns ama. Black pepper clears the channels so ojas can reach the deeper tissues.

Apples support the immune system because they contain antioxidants and both insoluble and soluble fiber, which cleanse the bowel. All sweet, juicy fruits (such as pears, peaches, plums, sweet pineapple and mangos) enhance 
immunity because they transform quickly into ojas. If they are tree-ripened, they convert almost instantly. Pomegranate seed juice and pomegranate seed chutney are also excellent boosters of immunity, because they enhance digestion and elimination without increasing Pitta dosha. A papaya after lunch enhances digestion and increases immunity.

Leafy greens such as Swiss chard, kale, mustard greens and spinach, when cooked and spiced with the immunity spice mix, are great immunity-boosters, because they provide iron, calcium and other nutrients while simultaneously cleansing the bowel. Broccoli, cabbage and cauliflower contain antioxidants, flavonoids and other immune-enhancing nutrients.

Whole grains such as quinoa, amaranth and barley also have immunity-fighting effects, because they provide cleansing fiber and contain many essential nutrients.

Last but certainly not least, ghee and milk are cherished in the ayurvedic tradition for their ojas-enhancing effects. Ghee is the most easily digested fat, contains essential fatty acids, and is a great immunity booster. Both milk and ghee should be organic and free of additives, and milk should be boiled with a pinch of cardamom before it is drunk in order to make it easier to digest. Drink it alone, away from meals, to avoid indigestion.

Cook your food but not too much

According to Maharishi Ayurveda, food becomes more digestible when you cook it. But you don't want to cook it too much, as that reduces its immune-boosting effect. The food should be soft and easy to chew, but not mushy.

Eat at the proper time
Eat your main meal in the middle of the day, when the sun is highest and digestion strong. Eat lighter at breakfast and at night, when digestion is weaker. This will enhance immunity.

It's also important to eat your meals at the same time every day. Your digestion gets used to a routine, and becomes more efficient.

\section{Eat the proper quantity}

Eating the right amount for your body type - not too much or too little - enhances ojas and supports the immune system. Maharishi Ayurveda recommends that you sip a cup of room-temperature water with your meals, so the meal is part liquid. Eat to only $3 / 4$ of your capacity, in order to leave some space for the digestive process to take place. If you eat until you are really full, it creates discomfort and ama.

Choose foods for your body type and for the season

It's not correct that you can eat anything you want, as long as it's good food. If you want to stay healthy, you need to choose foods that will bring balance to your body type and for the particular season. Whatever influences from the weather and climate are causing an imbalance, you need to counteract them with the food you eat.

Eating cold salads in winter (Vata season), for instance, is not a good idea, because raw salads only increase the cold, dry, light qualities of Vata, when what is needed is a warming, grounding, nourishing diet.

\section{REFERENCES}

WHO Q\&A on coronaviruses (COVID-19) March 2020, https://www.who.int/newsroom/q-a-detail/q-a-coronaviruses. 
Murphy A, and Bell D.J, et al. COVID-19, Radiopedia.

radiopaedia.org/articles/covid-19-

2? lang=us. 3. Singhal, T. A Review of Coronavirus Disease-2019 (COVID-19). Indian J Pediatr (2020). https://doi.org/10.1007/s12098-020- 03263b.

Center for disease controle and prevention, coronavirus disease 2019 (COVID-19). https://www.cdc.gov/ coronavirus/2019-ncov/symptoms-

testing/symptoms.html.

Velavan TP, Meyer CG. The COVID-19 epidemic. Trop Med Int Health. 2020;25(3):278-280. doi:10.1111/tmi.13383 https://

pubmed.ncbi.nlm.nih.gov/32052514/.

Countries where COVID-19 has spread, World ometers, 26March 2020. https://www.worldometers.info/coronavirus / countries-where-coronavirus-has-spread/.

Shereen M.A, Khan S, COVID-19 infection: origin, transmission, and characteristics of human coronaviruses Journal of Advanced Research, 16 March 2020. https://www.sciencedirect.com/science/a rticle/pii/S2090123220300540.

Age, Sex, Existing Conditions of COVID-19 Cases and Deaths. https://www.worldometers.info/coronavirus /coronavirusage-sex-demographics/.

Vally $\mathrm{H}$, The Conversion, La Trobe University. https://theconversation.com/why-areolder-people-more-at-risk-of-coronavirus133770.
Acharya Y.,
editor. Charaka
Samhita. Chaukhamba

Varanasi, India: 1992. Google Scholar. [Google Scholar]

Balasubramani S.P., Venkatasubramanian P., Kukkupuni S.K. Plant-based Rasayana drugs from Ayurveda. Chin. J. Integr. Med. 2011;17:88-94. [PubMed] [Google Scholar]

Cain P. How does your immune system work? World

Econ.

Forum. 2020 https://www.weforum.org/age nda/2020/04/immune-system-fight-offdisease-coronavirus-covid 19pandemic/ laccessed on 25 th April, 2020) [Google Scholar]

Chandran S., Dinesh K., Patgiri B. Unique contributions of Keraleeya Ayurveda in pediatric health care. J. Ayurveda Integr. Med. 2018:9:136-142. [PMC free article] [PubMed] [Google Scholar]

Medical Dialogues Bureau . 2020. Kerala Plans On Using Ayurveda To Mitigate COVID-19

Spread.https://medicaldialogues.in/statenews/kerala/kerala-plans-on-usingayurveda-to-mitigate-covid-19-spread64755 (accessed on 30th April, 2020) [Google Scholar]

Ministry of AYUSH, Government of India . 2020. Ayurveda's Immunity Boosting Measures for Self-care During COVID 19 Crisis. Online document at: http://ayush.gov.in/event/ayurvedaimmunity-boosting-measures-self-careduring-covid-19-crisis (accessed April 10, 2020) [Google Scholar] 